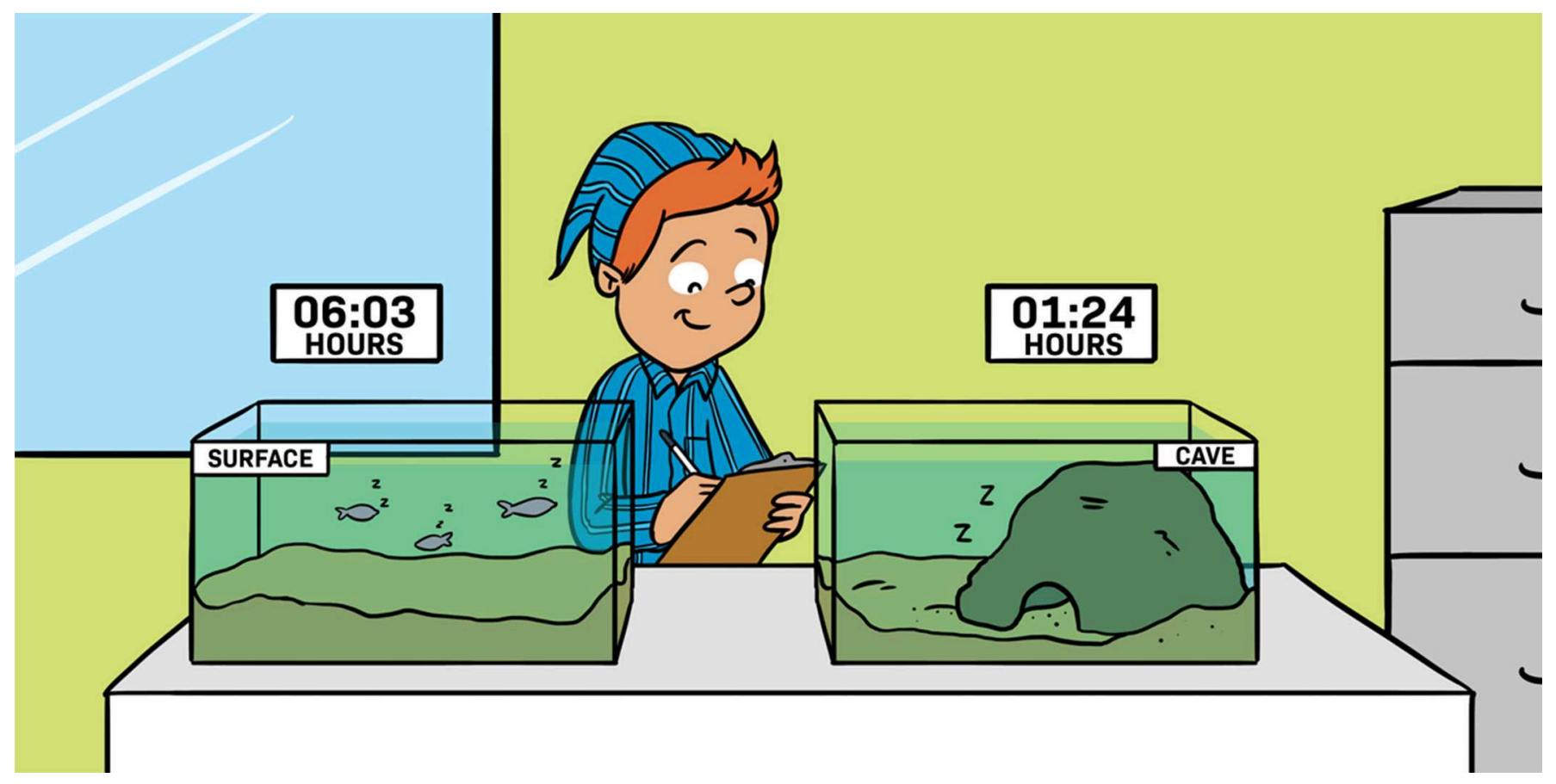

\title{
WHAT CAN A BLIND FISH TEACH US ABOUT SLEEP?
}

\section{Alexandra Paz and Alex C. Keene*}

Department of Biological Science, Charles E. Schmidt College of Science, Florida Atlantic University, Boca Raton, FL, United States

YOUNG REVIEWERS: EXPLORA SCIENCE CENTER AND CHILDREN'S MUSEUM AGES: 8-14
Nearly all animals studied to date sleep. It is widely accepted that sleep is critical for survival, yet the function of sleep remains unclear. Mexican cavefish have adapted in several ways for life in caves, but they have also evolved to sleep less than surface-dwelling fish. These fish are being used by scientists to investigate how sleep is regulated in response to an animal's environment. This article describes various experiments that can be conducted using cavefish to study sleep, and why these experiments might be useful to humans. The results of these experiments suggest that differences in sleep are influenced by a substance called hypocretin. Experiments, such as these help researchers to better understand how sleep has evolved over time and how to develop treatments for people suffering from sleep disorders.

\section{INTRODUCTION}

Sleep is a nearly universal behavior that has been defined in animals ranging from jellyfish to humans. Scientists regularly use animal 
Figure 1

An introduction to the Mexican cavefish. (A) Surface- and cave-dwelling fish are found in the Sierra de el Abra region of northeast Mexico. (B) A diagram of a typical cavefish. Both surfaceand cave-dwelling fish use their mouth, nose, and lateral line to sense their environment. However, because the cave-dwelling fish have no eyes, they must rely more heavily on these senses. (C) Surface fish live in the rivers of Mexico and southern Texas. These fish have normal eyes and pigmentation. (D) Pachón, (E) Molino, (F) Los Sabinos, and (G) Tinaja cave populations all have smaller eyes and reduced pigmentation, despite having evolved separately. Colored dots correspond to the locations of the caves shown in (A).

\section{ASTYANAX}

\section{MEXICANUS}

A fresh-water fish found in the rivers of Mexico and southern Texas. Blind populations of these fish are found in limestone caves in northeast Mexico.
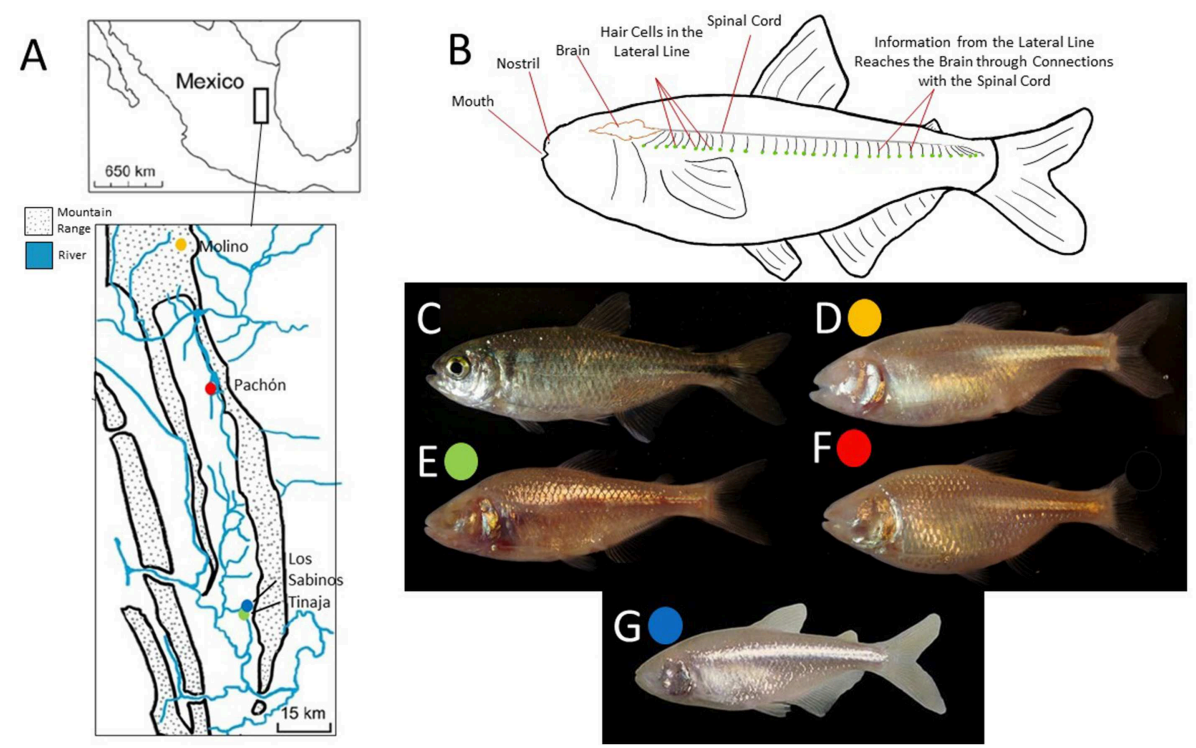

Figure 1

models, like fruit flies, zebrafish, and mice, along with sophisticated tools to alter genes, to study how the brain regulates sleep. These studies have found the genes and neurons (nerve cells) that control sleep are similar in all types of animals, suggesting that sleep has an ancient function that is critical for survival. Despite these findings, the function of sleep remains poorly understood. A central question for scientists is understanding how sleep evolves in different environments, and why some species, like elephants, only need a few hours of sleep each day while others, like armadillos, sleep most of the day [1].

Questions of evolution can often be addressed by identifying animals that have big differences from other animals, like those that need excessive or reduced amounts of sleep, and investigating the genes that play a role in these differences. Simple animals, like small fish, are often used in research on behavior, because their small size makes these experiments easier. The Mexican cavefish (scientific name Astyanax mexicanus) is especially useful for studying the evolution of behavior, because different populations of these fish have dramatic behavioral differences, from river-dwelling surface fish of the same species. These fish exist as at least 29 eyeless populations that live in caves and as eyed surface fish that live in the rivers of Mexico and Southern Texas (Figure 1) [2]. The cave-dwelling populations are probably surface fish that became trapped in the caves, resulting in eventual changes to their appearance and behavior. Despite being from completely different caves, the cave-dwelling populations evolved many of the same characteristics. Some of these characteristics are due to differences in brain structure and activity that have evolved to help the cavefish better cope with the cave environment. One interesting difference between the cave- and 
surface-dwelling populations of Mexican cavefish is in the amount of sleep each population gets. Cave-dwelling fish sleep significantly less than surface fish [2]. Because the populations are all the same species, they share many of the same genes, which makes it easier for scientists to identify the specific genes that cause the differences between the two populations. In this article, we will discuss how caveand surface-dwelling populations are used to study the evolution of sleep and why this research may shed light on the genes that control our own sleep habits.

\section{LIFE IN A CAVE}

There are some obvious differences between the rivers and caves inhabited by the different populations of $A$. mexicanus. Perhaps the most obvious is the lack of light in the caves, which are hidden from sunlight. The constant temperature in caves and the lack of sunlight prevents plant growth, which would normally form the bottom of the food chain. The two major sources of nutrition within the caves are probably bat droppings and nutrients that are swept into the caves during seasonal flooding [3].

The lack of light has another significant effect on cave inhabitants: eyes are not particularly useful. We believe that, when fish were first trapped in caves, those with smaller eyes were more likely to survive and produce offspring because smaller eyes helped them to save energy. After many generations, survival of fish with smaller eyes eventually resulted in fish that completely lack functional eyes [2]. Mexican cavefish and other organisms that lost their eyes this way rely on their other senses instead, like smell, taste, or sensing waterflow. Scientists wonder whether eye loss, and the changes in other senses that accompany eye loss, influence the amount of sleep cave-dwelling fish need.

\section{LATERAL LINE}

An organ used by fish to sense their environment. The lateral line is made up of collections of hair cells. When water pressure around the fish changes, the moving water causes these hair cells to move and send a signal to the fish's brain. The fish can use this information to get a sense of its surroundings.

\section{WHY DO CAVE-DWELLING FISH SLEEP LESS?}

Lab experiments have shown that surface fish sleep about $6 \mathrm{~h}$ per day, while cave-dwelling fish sleep $<2 \mathrm{~h}$ per day (Figure 2) [4]. Why did cave-dwelling fish evolve to spend less time sleeping? One possibility is that cave-dwelling fish have evolved to sleep less as a way of dealing with nutrient limitation. As we discussed above, in caves, there are no plants for the fish to eat and nutrients may not always be readily available. Sleeping less allows the fish more time to search for food. Cave-dwelling fish will also sleep more when their lateral line, a major sensory organ that detects prey, is made non-functional [5]. The lateral line consists of hair-like structures connected to neurons that detect vibrations or flow in water (similar to pressure receptors in human skin) and transmit this information to the brain. Because the lateral line is believed to be the major sense used by cave-dwelling fish to find food, 
Figure 2

Measuring sleep in cavefish. (A) Either a cave- or surface-dwelling fish is placed in a tank and their behavior is recorded. These recordings are analyzed using computer software that tracks the activity of the fish. When the fish go at least a minute without moving we can assume they are sleeping. (B) Measuring the sleep duration over $24 \mathrm{~h}$ reveals sleep in surface-dwelling fish (black) is reduced compared with Pachón cavefish (blue) during the day and night. The shaded portion of the graph shows when the fish are in the dark (to simulate the natural day-night cycle)

\section{FLUORESCENCE}

The emission of light. Some proteins, like those found in jellyfish, will emit light when they are exposed to light of certain colors Scientists use fluorescent proteins to mark specific cells or brain regions, and then observe those cells or regions under a microscope.

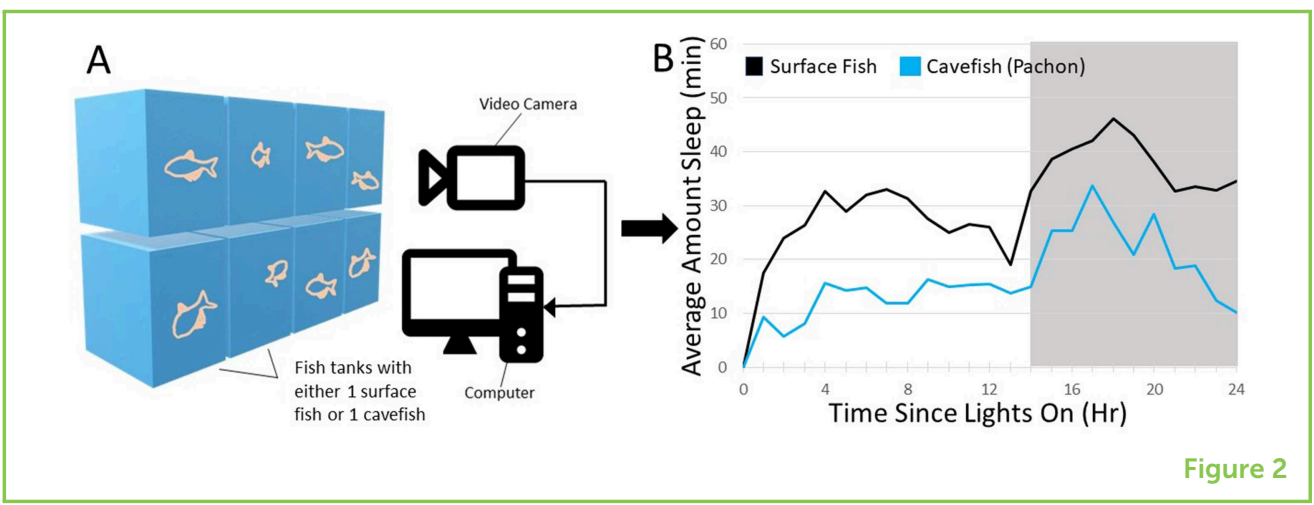

this supports the idea that nutrient availability has played a part in the evolution of this difference in sleep.

Our ability to prove or disprove this hypothesis is limited by our lack of complete understanding of the fish's natural environment. In the lab, fish are raised under constant, controlled conditions that are very different from the conditions of a river or cave. In the lab, fish are kept in standard fish tanks with light provided for $10 \mathrm{~h}$ each day. While keeping both types of fish in the same conditions is essential for experiments comparing surface- and cave-dwelling fish, this procedure may not reflect the animal's natural environment. For this reason, scientists are organizing expeditions into the caves to gather data on how things like temperature and nutrient levels vary over time. These experiments are difficult, because the caves are isolated and often difficult to access. Further, measuring sleep behavior in the wild is especially challenging. In a recent expedition, we collected water samples from several caves and will compare the DNA in the water, which will tell us about the animals and plants that live in each cave. Using information taken from cave expeditions, scientists will be able to better understand the significance of lab findings and design new experiments to test the effects of specific environmental factors, like food availability or temperature, on the evolution of different sleep patterns in surface- vs. cave-dwelling fish.

\section{WHAT KIND OF TECHNIQUES CAN WE USE TO STUDY SLEEP IN CAVEFISH?}

Scientists often identify differences in brain function using sophisticated ways of looking at the brain. One way is by using fluorescence, meaning chemicals that emit light, to label parts of the brain that have specific types of neurons. Essentially, scientists take a fluorescent gene (usually from jellyfish) and use special techniques to have it produced in specific types of neurons in the fish. This technique causes the target neurons to glow under a special type of microscope. Scientists can then look for differences in the size, shape, or number of neurons in the cave-dwelling vs. surface-dwelling fish. These types of differences in 


\section{Figure 3}

Levels of the small protein hypocretin (hcrt), which prevents sleep, are increased in cavefish. (A) To measure hypcretin levels within the brain, the brain is dissected out of the fish and then sliced. The brain slices are then labeled with a fluorescent chemical so the cells can be seen using a special microscope. (B,C) Comparing brain slices from surface-dwelling fish (B) and

cave-dwelling fish (C) show that levels of hypocretin protein (HCRT, green) are higher in cave-dwelling than in

surface-dwelling fish

(D) The number of

HCRT neurons is greater in

cave-dwelling fish and blocking hort activity in cave-dwelling fish caused them to sleep more. Blocking hcrt activity in surface fish did not influence their sleep. Adapted from Jaggard et al. [6].

\section{HYPOCRETIN}

A small protein secreted by neurons to communicate with other neurons. Hypocretin promotes wakefulness. Humans and dogs that lose hypocretin function develop a sleep disorder called narcolepsy.

\section{GENOME}

All of the genes and genetic material within an organism.
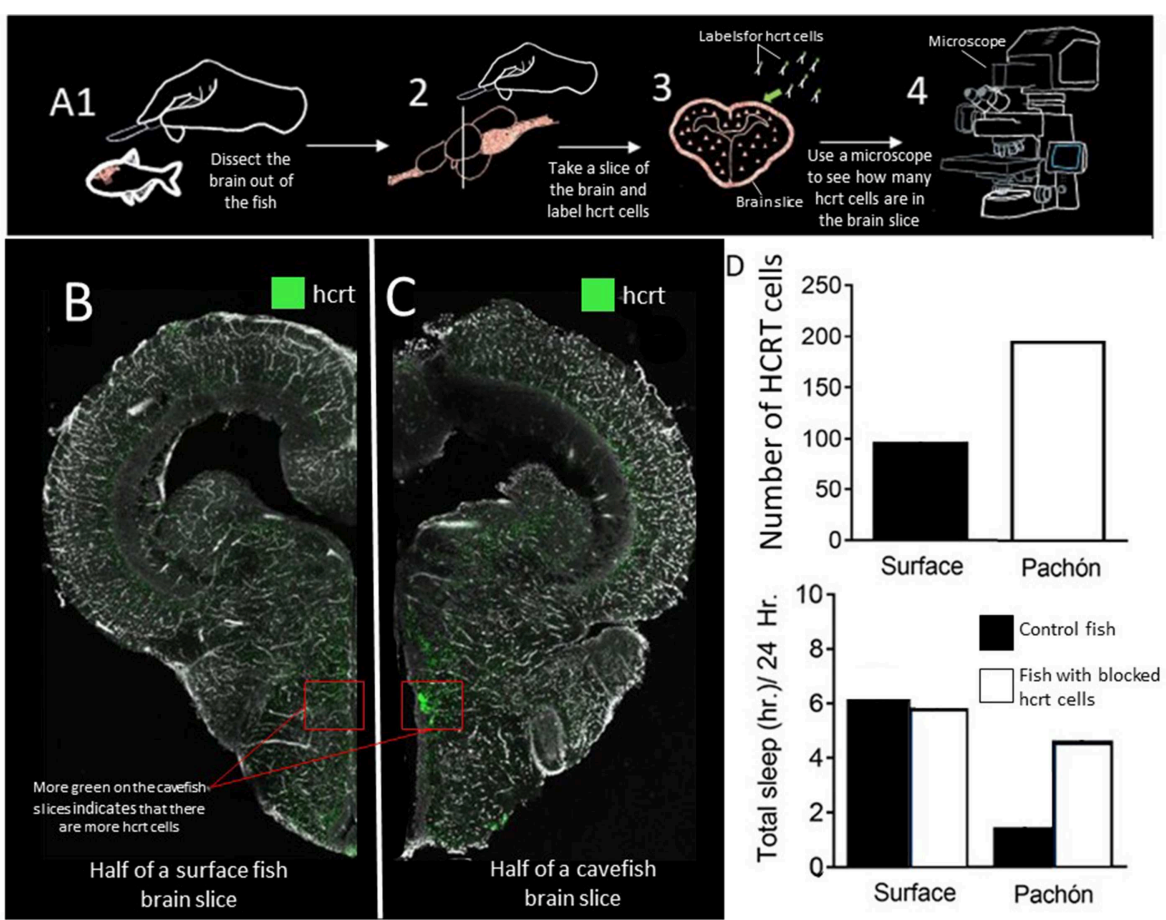

Figure 3

neurons between the populations can provide clues to how the brain is regulating the behavior of the fish. For example, we used fluorescence to label the neurons that produce hypocretin, a small protein that prevents sleep. We found that cave-dwelling fish brains have more neurons that produce this peptide than surface-dwelling fish brains (Figure 3) [6]. These findings suggest that hypocretin may have evolved to reduce sleep in cave-dwelling fish.

Because cave-dwelling and surface-dwelling fish are so similar, comparing their genomes (all of their genes) is a powerful way to identify genes that might be controlling different behaviors, like sleep. Once a gene of interest has been identified, scientists can use special techniques to delete, modify, or insert genes into fish embryos, to create genetically modified animals [7]! For example, these techniques have been used to reduce hypocretin in the brains of cave-dwelling fish, which resulted in increased sleep [6]. Doing the same experiment in surface-dwelling fish, however, had no effect. These data strengthen the possibility that hypocretin is involved in the difference in sleep between cave- and surface-dwelling fish.

Scientists can also breed cave-dwelling fish with surface-dwelling fish, to create hybrid fish that are interesting to study. These fish have variable appearance and sleep duration. By testing each fish for sleep and then sequencing its genome, a process called quantitative trait loci mapping, scientists can identify regions of the genome (and sometimes individual genes) that regulate sleep [8]. For example, if a scientist tests 2,000 fish and most of the fish that do not sleep share a 


\section{QUANTITATIVE} TRAIT LOCI

A statistical analysis that associates a specific genetic change with a trait, like sleep or eye size. certain gene, this gene would be identified as potentially contributing to sleep. That gene could then be studied in more detail to investigate how it influences sleep.

Another powerful technique to study sleep in cavefish is drug screening. Fish are bathed in different drugs, to try to find drugs that can make cave-dwelling fish sleep more.

Together, these techniques for studying sleep in cavefish can help us to understand why cave-dwelling fish sleep less than surface-dwelling fish. While we have learned a lot about the sleep differences between these two types of fish, there is still a lot of work to be done!

\section{WHAT CAN CAVEFISH DO FOR US?}

There is significant variation in sleep across the animal kingdom. For example, elephants only sleep 3-4h per day, while brown bats sleep about $20 \mathrm{~h}$ per day. Even among humans there is variation in sleep, with some people getting $<5 \mathrm{~h}$ and others getting more than $10 \mathrm{~h}$. Despite this variation, regulators of sleep are the same in different kinds of organisms, including people and cavefish. Hypocretin, for example, has been associated with human sleeping disorders. For this reason, understanding how sleep is regulated in cavefish can help scientists understand how sleep is regulated in humans. Animals like cavefish can help us understand not only why there is so much variation in sleep among people, but also the mechanisms behind various sleep disorders. Further, cavefish could be used to screen for drugs to test whether those drugs might work for sleep disorders in people.

\section{ORIGINAL SOURCE ARTICLE}

Jaggard, J. B., Stahl, B. A., Lloyd, E., Prober, D. A., Duboue, E. R., and Keene, A. C. 2018. Hypocretin underlies the evolution of sleep loss in the Mexican cavefish. eLife 7:e32637. doi: 10.7554/eLife.32637

\section{REFERENCES}

1. Siegel, J. M. 2005. Clues to the functions of mammalian sleep. Nature 437:1264-71. doi: 10.1038/nature04285

2. Gross, J. B. 2012. The complex origin of Astyanax cavefish. BMC Evol. Biol. 12:105. doi: 10.1186/1471-2148-12-105

3. Keene, A. C., Yoshizawa, M., and McGaugh, S. E. 2015. Biology and Evolution of the Mexican Cavefish. Waltham, MA: Elsevier Inc.

4. Duboué, E. R., Keene, A. C., and Borowsky, R. L. 2011. Evolutionary convergence on sleep loss in cavefish populations. Curr. Biol. 21:671-6.

doi: 10.1016/j.cub.2011.03.020 
5. Jaggard, J., Robinson, B. G., Stahl, B. A., Oh, I., Masek, P., Yoshizawa, M., et al. 2017. The lateral line confers evolutionarily derived sleep loss in the Mexican cavefish. J. Exp. Biol. 220:284-93. doi: 10.1242/jeb.145128

6. Jaggard, J. B., Stahl, B. A., Lloyd, E., Prober, D. A., Duboue, E. R., and Keene, A. C. 2018. Hypocretin underlies the evolution of sleep loss in the Mexican cavefish. eLife. 7:e32637. doi: 10.7554/eLife.32637

7. Klaassen, H., Wang, Y., Adamski, K., Rohner, N., and Kowalko, J. E. 2018. CRISPR mutagenesis confirms the role of oca2 in melanin pigmentation in Astyanax mexicanus. Dev. Biol. 441:313-8. doi: 10.1016/j.ydbio.2018.03.014

8. Yoshizawa, M., Robinson, B. G., Duboué, E. R., Masek, P., Jaggard, J. B., O'Quin, K. E., et al. 2015. Distinct genetic architecture underlies the emergence of sleep loss and prey-seeking behavior in the Mexican cavefish. BMC Biol. 13:15. doi: 10.1186/s12915-015-0119-3

SUBMITTED: 01 February 2019; ACCEPTED: 16 July 2019; PUBLISHED ONLINE: 02 August 2019.

EDITED BY: Kathleen Y. Haaland, University of New Mexico, United States

CITATION: Paz A and Keene AC (2019) What Can a Blind Fish Teach Us About Sleep? Front. Young Minds 7:103. doi: 10.3389/frym.2019.00103

CONFLICT OF INTEREST STATEMENT: The authors declare that the research was conducted in the absence of any commercial or financial relationships that could be construed as a potential conflict of interest.

COPYRIGHT @ 2019 Paz and Keene. This is an open-access article distributed under the terms of the Creative Commons Attribution License (CC BY). The use, distribution or reproduction in other forums is permitted, provided the original author(s) and the copyright owner(s) are credited and that the original publication in this journal is cited, in accordance with accepted academic practice. No use, distribution or reproduction is permitted which does not comply with these terms.

\section{YOUNG REVIEWERS}

\section{EXPLORA SCIENCE CENTER AND CHILDREN'S MUSEUM, AGES: 8-14}

The Explora Young Minds reviewers are a group of science enthusiasts working with museum educators and mentors from the University of New Mexico. We enjoy learning about the brain through the articles. We also enjoy asking questions and making suggestions to help the scientists make their work more understandable for everyone! We were helped by our Science Mentor Jennifer Walter. She just received her Ph.D. in pediatric neuropsychology. She enjoys working with kids, playing with her dog, and trying to cook new recipes. 


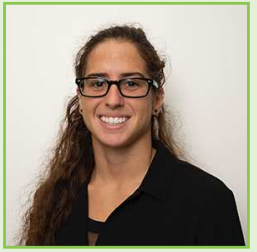

\section{AUTHORS}

\section{ALEXANDRA PAZ}

I am a Ph.D. student studying neuroscience at Florida Atlantic University. After graduating from St. Bonaventure University with my Bachelors in Biology, I worked as a hydrologic technician in Everglades National Park. Right now, I am working toward getting my Ph.D. so that one day I can have my own lab to conduct research and give students of all ages the opportunity to experience how exciting science can be. When I am not in the lab I like to swim, boat, and play video games.

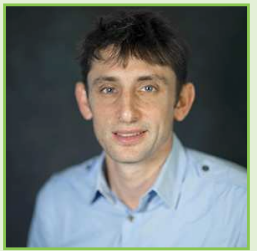

\section{ALEX C. KEENE}

I am an Associate Professor of Biological Science at Florida Atlantic University where I direct the summer Research Experience for Undergraduates (REU) and Neuroscience B.S. programs. I received my Ph.D. from UMass Medical School in 2006 where I studied how memories are formed in fruit flies. My lab studies many different aspects of neuroscience including memory, sleep, taste, and aging. I find that the best part of science is the collaboration and teamwork that takes me all over the world. *alexckeene@gmail.com 